\title{
Feedback for Thought: Examining the Influence of Feedback Constituents on Learning Experience
}

\author{
Chadi Aoun \\ Carnegie Mellon University, Qatar \\ chadi@cmu.edu \\ Savanid Vatanasakdakul \\ (Corresponding author) \\ Macquarie University, Australia \\ Savanid.Vatanasakdakul@mq.edu.au \\ Karyne Ang \\ University of Technology Sydney, Australia \\ Karyne.Ang@uts.edu.au
}

\begin{abstract}
Reflective teaching practice is often heralded as a pillar of effective tuition. However, the perceptions of multiple forms of feedback among learners and their contributions to reflective learning is yet to attract significant attention, particularly in the IS context. This research investigates the antecedent constituents of feedback and how they contribute to an overall perception of feedback in an introductory IS course. A research model grounded in the pedagogical literature was operationalised and quantitative data collected and analysed using PLS. The results indicate that summative and generic assessment feedback were found to be significant towards formulating an overall perception of feedback, and that such perception is significant in influencing a learner's experience. This further highlights the fact that students are overwhelmingly assessment focused and may not engage in reflective practice pertaining to their overall learning experience - necessitating the establishment of Learner's reflective lenses to guide them towards such reflection.
\end{abstract}

\section{Keywords}

Feedback Constituents; Learners' Perception and Experience; Lenses for Reflective Learning; Information Systems Education; PLS 


\section{Introduction}

Feedback is a fundamental prerequisite for reflection (Quinton and Smallbone 2010; Higgins, Hartley and Skelton 2002; Mutch 2003), and a cornerstone of effective learning and teaching (Hattie, Biggs, and Purdie 1996; Sadler 1998; Black and William 1998). This introduces pertinent and persisting challenges to curricular designers and instructors to provide students with timely and diverse opportunities to attain feedback that would facilitate and deepen reflective learning processes. Consequently, feedback mechanisms have attracted significant research interest, spanning from studies on the design and provision of summative and formative feedback (Harlen and James 1997), to peer assessment and feedback (Boud, Cohen and Sampson 1999), and to forward and upward feedback mechanisms (Hounsell, McCune, Hounsell and Litjens 2008), to name a few. However, while such studies have proven invaluable in presenting and recommending effective practice for curricular designers and instructors to adopt, several deficiencies still persist, at the forefront of which is the perception of effective feedback by the learners. From a practical viewpoint, student learning from feedback could be enhanced by inducing the link between reflective practices and feedback mechanisms, which improves their learning experience. Integrated with feedback mechanisms is the need for reflective practice to guide student learning. It is viewed that feedback is only effective if it results in some form of reflective knowledge building, that is, monitoring and evaluation in order to elicit and support further knowledge building (Nicol 2013). Prescribing effective practice for feedback in teaching delivery is therefore best complemented with an understanding of how such feedback mechanisms are perceived and reflected upon by the learners, in order to achieve a comprehensive view of effective teaching and learning. The literature deficiency in the latter is the subject of this study.

This study is empirically contextualised in a first year Introduction to Information Systems course at a large Australian university (it is noted that the terms 'subject' or 'unit' are often used in the Australian context to describe an academic topic of study that a student usually undertakes over the period of a semester as part of their degree, however, while these terms are used interchangeably, the term 'course' is used here to accommodate a broader international readership). The study was partially motivated by the fact that, although a myriad of feedback mechanisms were incorporated in the course (including in-class feedback in lectures and tutorials, peer assessment and feedback tasks, and feedback on individual and group assessment activities) university administered student evaluation forms only incorporated a single question on feedback, which inquires about whether a student found the feedback to be effective. Unfortunately, this did not provide for a clear understanding of which feedback mechanisms, including formative, summative, individual and generic mechanisms, were viewed as important and relevant from the students' perspective. Such deficiency motivated an investigation of the extant literature which led to the identification of the literature gap, and influenced the initiation of the study. Consequently, we aimed to respond to the following research questions: First, what feedback mechanisms are perceived as important by students in an introductory IS course? And second, does an overall perception of positive feedback contribute to a favorable experience in such course?

In addressing these questions, the paper commences by providing a brief overview of the literature followed by the development of relevant hypotheses; the research methodology is then presented along with the empirical results; this is followed by the discussion, implications, and conclusion sections.

\section{Literature Review}

In traversing the literature, it is vital to recognise the different definitions and conceptualisations of feedback. Hattie and Timperley (2007, p.81) conceptualise feedback as 'information provided by an agent (e.g., teacher, peer, book, parent, self, experience) regarding aspects of one's performance or understanding'. They view feedback as a resulting consequence of performance relating to one's assessed skill, abilities or understanding (Hattie and Timperley 2007). Furthermore, in educational contexts feedback is generally recognised as a crucial means by which to improve knowledge, build on student skills (e.g., Azevedo and Bernard 1995; Epstein, Lazarus, Calvano, Matthews, Hendel, Epstein and Broswic 2002; Moreno 2004; Pridemore and Klein 1995) and facilitate independent life-long learning that continues into professional practice beyond formal educational settings (Ferguson 2011; Hounsell 2003).

For others, feedback is seen as a central part of learning (Cramp 2011) and conceptualised as a supported sequential process rather than a series of isolated events (Archer 2010). In contrast, the idea of feedback as part of a continuous process to support learning that progresses into professional practice beyond higher education can also be identified by the terms feed-forward and feed-up, respectively (Hounsell et al. 2008). Consequently, many studies have shown 


\section{Feedback for Thought}

feedback to be an essential part of learning, as it specifically relates to performance and thereby enables improvement and higher-order learning (Sadler 1998). It has been shown that feedback is one of the most effective means of promoting transformative learning (Harvey and Knight 1996), and that students themselves value quality feedback (Horsburgh 1999; Hyland 2000; O’Donovan, Price, and Rust 2004).

From the literature reviewed, there is an overall implicit dominant notion that the provision of feedback will necessarily lead to improvements in subsequent pieces of work. High quality feedback is positioned as an overriding influence on student achievement (Brown and Knight 1994; Hattie 1987) which increases the probability that deep learning will happen (Hattie and Jaeger, 1998). In pedagogical circles, these assumptions are proposed as 'uncontestable truths' and 'common sense'. A study by Crisp (2007), for example draws on her experiences to comment that, should students fail to perform adequately, it is often assumed that the teacher might have failed to provide adequate feedback. However, despite the noble intentions of educators in providing adequate feedback, there is also the issue of whether students are able to recognise, grasp, interpret, and reflect upon the types of feedback provided in a meaningful manner that meets their expectations. Recent research has emphasised that it is also about how students make sense of the importance of the feedback received (Higgins, Hartley and Skelton 2001; Orsmond, Merry and Reiling 2002) and whether or not they actively engage with the feedback (Orsmond, Merry and Callaghan 2004). Other factors affecting the ability of students to respond to the feedback include the tone of feedback (Read, Francis and Robson 2005) and receiving too much feedback, which leaves them feeling overwhelmed (Brockbank and McGill 1998). Furthermore, some would argue that not all feedback is good feedback since feedback is a complex process and may have both positive and detrimental impact on student performance depending on the learning setting, tasks at hand and the student's own attitudes and motivations towards the tasks (Nicol 2013). Nicol (2013) adds that the potency of feedback is contingent on context, timing, the recipient and provider attributes and skills.

Yet, a distinction needs to be made to clarify what constitutes feedback in the gamut of instruction and feedback as highlighted by Hattie and Timperley (2007). In their opinions, feedback happens as a second part of the teaching process - after a student has responded to instruction. It is a consequence of students' performance, in order to construct and relate new information to what is already known. The writers quote Winne and Butler (1994, p. 5740) to surmise that "feedback is information with which a learner can confirm, add to, overwrite, tune, or restructure information in memory, whether that information is domain knowledge, meta-cognitive knowledge, beliefs about self and tasks, or cognitive tactics and strategies". Adding on to the work of Ramaprasad (1983) and Sadler (1989), feedback is seen to bridge the gap between actual performance levels and the anticipated learning goals (Lizzio and Wilson 2008). In essence, feedback is acknowledged widely in the literature as critical in the development of effective learning (Black and Wiliam 1998; Hattie et al. 1996; Hattie and Jaeger 1998). Feedback can thus be defined as information conveyed to the learner with the intention of modifying his or her thinking or behavior to improve learning (Shute 2008, p.154) with the addendum that it needs to be delivered correctly. With this in mind, good feedback practices can facilitate self-assessment or reflection on learning (Nicol and Macfarlane-Dick 2006) and indicate a learning pathway which students can build upon (Hyland 2000).

Significantly, for some, it is only feedback if it bridges the knowledge gap and has an impact on learning (Draper 2009; Wiliam 2011). In order for learners to be able to identify gaps in their learning and build, create or reconstruct knowledge, learners need to be provided with clear and explicit opportunities to reflect on and evaluate their own performance in relation to feedback, regardless of how the feedback is generated (Nicol 2013). However this will still not guarantee that students will reflect on, and learn from, the feedback. The provision of feedback is only one component. It is also dependent on what the student recognises, does or is willing to do with the information provided. From a cognitive perspective offered by Nicol (2013), what goes on in the student's mind and what it leads them to do also impacts on the effectiveness of the feedback. This is where reflective practice is important in self-evaluation and generating inner feedback mechanisms, and an overall positive learning experience. What is missing in the literature is an investigation of feedback mechanisms provided in various learning settings and whether this impacts student perceptions of feedback and hence their overall reflective experience in a course. The mechanisms of feedback in this study delve into the deconstructed functional elements that focus on the process, vehicle or mode of delivery or in simpler terms, the feedback activities. We acknowledge that feedback practices encompass a wider range of considerations beyond mere processes including the nature and quality of feedback, and who provides it (for example, the teacher, a peer or self-generated) and how it is provided (Nicol and MacfarlaneDick 2006). Effective feedback goes beyond the abilities and skills of the educator to provide feedback. Rather it is also about engaging learners as active players in the process (Butler and Winne 1995, Boud 2000, Hounsell 2007, Nicol 2013) and their abilities to reflect on the feedback received. Moreover, while significant emphasis has been 
placed on the merits of a reflective teacher (Brookfield 1995), feedback that enable reflective learning is yet to garner attention. It seems to be simply assumed that students need to reflect on their learning - albeit with no clear guidelines for such reflection. Feedback and reflection are a particularly important focus for our study because the effective and regular reflection on feedback remains a fundamental mechanism for making new university students feel supported, accustomed to and comfortable within the university environment (Long, Ferrier and Heagney 2006).

\section{Research Model and Hypotheses Development}

Our paper situates the research on student feedback perceptions within a model of first year learning experiences. A research model proposed by this study is presented in Figure 1. The model comprises of 5 elements of feedback (H1-H5) in an IS course which are investigated to measure their impact on students' overall perception of feedback, and as a result, their overall perception of learning experience in the course (H6). Overall, we posit that a favourable perception of feedback received will lead to a positive overall experience in a first year IS course. These hypotheses are explained in further detail in the next sections.

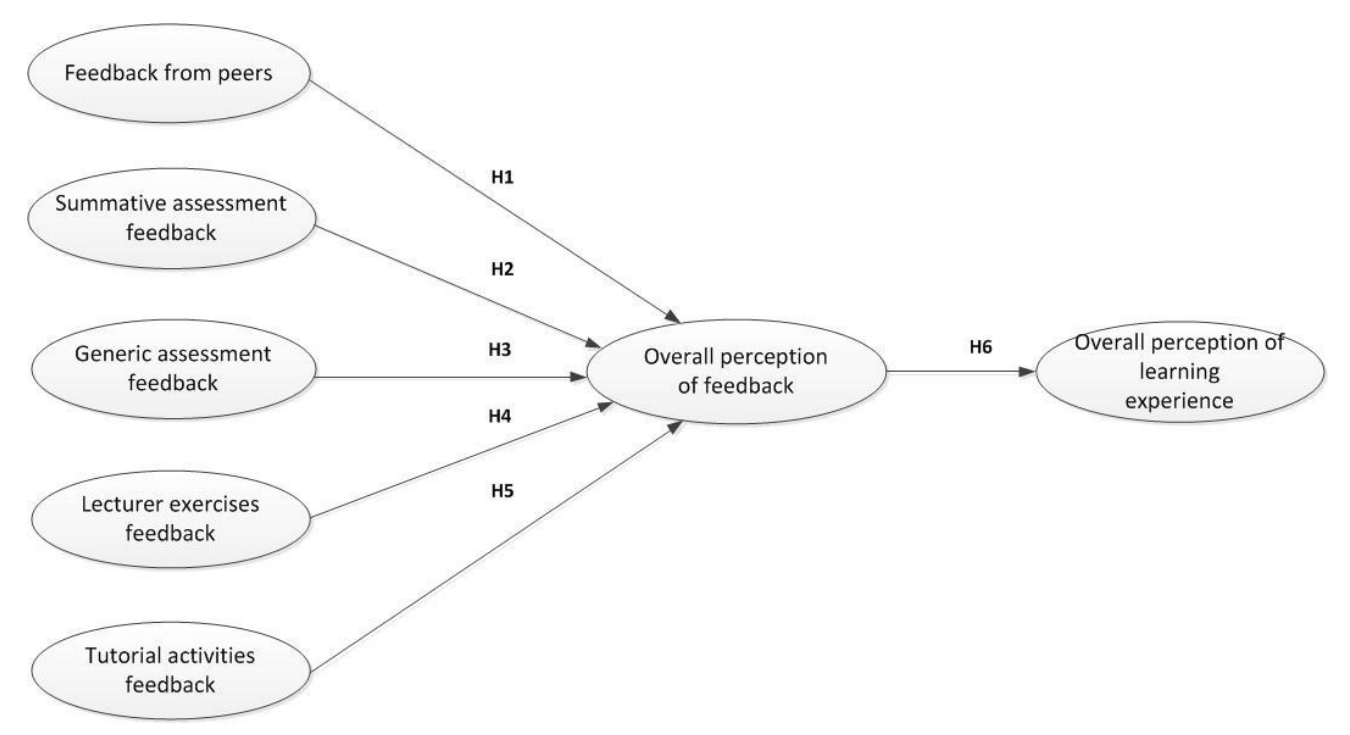

Figure 1: Research Model

\section{Feedback from Peers}

There is a large body of complementary research studies demonstrating the effects of self and peer feedback on learning (e.g. Boud 1995; Boud, Cohen and Sampson 1999). Peer feedback is said to promote student-centered learning, encourage students to produce their work for a larger audience, and may reduce teacher workload by reducing personalised feedback to every student (DiPardo and Freedman 1988). Vygotsky (1978) argues that interactions with more abled peers can help students reach their full potential through what he called students' 'zone of proximal development'. He states that through peer collaboration, students' developmental levels are likely to progress. Some suggest that the introduction of some element of peer assessment may help students to become more familiar with the meanings of the criteria upon which their work is evaluated (Higgins, Hartley and Skelton 2002). They can then accurately estimate their academic work, assess their progress, and adjust their learning strategies accordingly.

Within higher education, a recently new practice of feedback has been identified, evidenced by peer assessments utilised to promote student self-regulatory practice (Cartney 2010; Nicol 2010; Rust 2007). It is said that involving pupils in their own assessment means that they are expected to reflect on the aims of their learning. Pupils are said to be able to develop understanding of learning objectives and achievement criteria through experiences designed to involve them in looking critically at their own work (Harlen and James 1997). The course provided students with 
regular opportunities to receive feedback from peer in weekly tutorial activities (weekly) and quiz work. For example, a formative paper-based quiz with open ended questions was conducted. Tutors guided students through peer marking it, with anecdotal feedback indicating that students found it very insightful as it encouraged them to reflect on their own work in comparison to that of other students. Therefore, a hypothesis applied in this study is that peer feedback has a positive impact on students' overall perception of feedback.

H1: Feedback from peers is likely to lead to an overall positive perception of feedback in an IS course.

\section{Summative Assessment Feedback}

Summative assessment is viewed as having a quite different purpose compared to formative feedback (Harlen and James 1997). It describes the learning achieved by students at a certain time "for the purposes of reporting to parents, other teachers, the pupils themselves and, in summary form, to other interested parties such as school governors or school boards" (p.370). It is perceived by educators to have an important role in the overall educational progress of pupils but not in everyday teaching compared with formative assessment. However, it has been suggested that an extensive proportion of students focus on the marks received, with the assessment comments being of only secondary concern. For such students, feedback may only be acted upon if there is a desire to acquire a better mark on a subsequent occasion (Smith and Gorard 2005). Students in this course received summative feedback on case-study based assignments (55\%), examination (40\%), and class participation (5\%). Our hypothesis tested in this matter is that:

H2: Summative assessment feedback is likely to lead to an overall positive perception offeedback in an IS course.

\section{Generic Assessment Feedback}

Generic feedback is useful for teachers to modify instruction for the whole class and for students to see how they are generally progressing. Knight and Yorke (2003) note that "although many teachers give a lot of feedback on specifics, it is general feedback that has the greater power to stimulate learning” (p. 33). Such feedback has the potential to 'feed-forward', into future tasks rather than back to completed assignments.

Others found that while students desire feedback that provides them with a grade, they also seek feedback which focuses on generic, 'deep' skills (Higgins et al 2002, p.60). Additionally, optimal feedback for formative use may not necessarily be specific, detailed, positive, and individualised (Jonsson 2012), as is often assumed (Gibbs and Simpson 2004; Race 2007). Instead, less specific and individualised feedback, which forces the students to actively engage with the information, may actually be more productive for student reflective learning. Therefore, generic feedback positioned as formative and provided in a collective manner could support students' learning. Students in this course received very detailed generic feedback on their assignments, both documented and verbal, where key guidelines and common mistakes were explained, along with references to relevant study materials and learning objectives. The hypothesis formulated in this instance is:

H3: Generic assessment feedback is likely to lead to an overall positive perception of feedback in an IS course.

\section{Lecture Exercises Feedback}

In contrast to traditional lecture formats aimed at broadcasting course content material to large class groups, lecture exercises have been found to stimulate and enhance learning (Butler, Phillmann and Smart 2001). In lecture exercise, students are said to benefit from timely feedback on applied classwork, shared ideas and connect with other students (Bonwell 1996; McKeachie 1999). Furthermore, feedback in this mode enables students the opportunity to identify and engage with the standards and criteria of the course, and subsequently to use these in improving their work. It can be postulated therefore that feedback provided within lecture exercises could influence student overall perceptions of feedback. The lecture incorporated small exercises (requiring about 5 to 10 minutes each) which students engage with at multiple intervals during the lecture, discuss their suggestions, and receive instantaneous feedback and guidelines ferom the lecturer. This leads to our hypothesis that:

H4: Feedback on lecture exercises is likely to lead to an overall positive perception of feedback in an IS course. 


\section{Tutorial Activities Feedback}

Engagement of students through active learning is said to facilitate learning processes (Bloom and Krathwohl 1956; McKeachie 1994; Weimer 2002). For example, active learning assignments in the form of in-class writing activities for psychology students were tested and found to enhance student learning, retention, and writing development (Stewart, Myers and Culley 2009). Feedback in this instance was provided to students on content and quality. Other attempts at class activities were also outcomes focused although interventions that investigated self-generated feedback impacting the development of meta-cognition, knowledge integration and self-efficacy can also be considered (Nietfeld, Cao and Osborne 2006). Overall, the literature on feedback is scant in terms of past attempts in exploring the various forms of feedback within tutorial activities and ultimately how student overall perceptions of feedback are impacted by feedback provided within such activities. In the IS course that was investigated, these activities were designed around small class groups that the students regularly work with, compared to lecture exercises where students engage with a larger cohort of students. Tutorials lasted for 1.5 hours per week. Tutorial activities were constructively aligned with case-based assessments and were predominately case-based. Solution guidelines were often derived from student's solutions, facilitated by the tutor, at the end of each tutorial. In this study, the hypothesis tested within the context of tutorial activities is as follows:

H5: Feedback through tutorial activities is likely to lead to an overall positive perception of feedback in an IS course.

\section{Overall perception of learning experience of an IS course}

It is said that assessment generates most student attention and inquiries (Reynolds and Trehan 2000) since assessment is viewed by students as central to their university experience. One of challenge teachers face is to find ways to encourage their students to both heed and reflect on the feedback in order to learn and enjoy their learning experience. The question is how do students view feedback? At which point is the learning process a feedback mechanism, and do students recognise this as part of their learning experience? Research by Beaumont, O'Doherty and Shannon (2011) show that students experience a radically different culture of feedback in schools and higher education, with the former providing extensive formative feedback and guidance, while the latter focuses upon independent learning that is often judged summatively.

Within higher education, feedback is provided to students with the expectation that this will promote learning and lead to improvements in subsequent pieces of work prepared by the student (Orsmond, Merry and Reiling 2005). Past studies have shown that student perceptions of instructor feedback have a favourable impact on student satisfaction, learning outcomes and perceived learning overall (Eom, Wen and Ashill 2006; Hackman and Walker 1990; Richardson and Swan 2003). These previous studies were conducted in the context of online learning. Nevertheless, feedback is a motivating factor to students in general, which is expected to contribute to the enhancement of their overall learning experience in a classroom context. Therefore, our final hypothesis is as follows:

H6: An overall favourable perception of feedback is likely to lead to a positive experience in an IS course.

\section{Methodology}

This research adopts a positivist research approach incorporating a quantitative methodology and methods. Inline with such approach, hypotheses were derived from the scientific literature and were empirically tested using a survey instrument. Data collected were analysed using Structural Equation Modeling (SEM) with the Partial Least Squares (PLS) technique. The model was operationalised and analysed in SmartPLS 2.0. The PLS approach was preferable for this study because it provides a better predictive capability and it is effective in the analysis of a high complexity model with a small sample size, compared to a large number of independent variables. In addition, it imposes no requirement for a normal distribution assumption, which suits the nature of the data collected (Chin, 1998). All the items were measured based on a five-point Likert scale ranging from strongly disagree to strongly agree and were operationalised as reflective indicators. The constructs and their measurement items are newly developed based on the relevant literature. All items are reflective measurements. Table 1 below summaries the definitions of each construct. 


\section{Feedback for Thought}

Empirical data were collected over the period of one month, at the end of semester 1 (March to June) 2013. The Introduction to IS course where the data was collected from, was offered in 3 hour face-to-face sessions, consisting of a weekly 1.5 hour lecture (led by the instructor and accommodating around 200 students over two streams) and 1.5 hour tutorials (with around 30 students per tutorial session led by a tutor and based on practical exercises and cases). The cohort consisted of 402 students (potential participants), of which 80 students provided complete surveys. This converts to about a $20 \%$ response rate which is reasonable for a study of this nature. It is worth noting that the survey administration and data collection and management were authorised by the University's committee on human ethics, which ensures that no adverse effects are likely to arise due to this research. The research design stipulated anonymity and all participation was voluntary. The survey was placed on Survey Monkey (a web based survey engine) and potential participants were provided with a generic link. Only generic data were sought with which participants cannot be identified.

In terms of participants' demographical information, 73 percent of the valid respondents were male and 26 percent were female; 84 percent had an age range between 18-24 years old; and 99 percent of the participants were full-time students. The majority of the participants were domestic students ( 85 percent), while 15 percent were international students. The PLS analysis and results of the data collected are discussed in the following section.

Table 1 Construct definition

\begin{tabular}{|c|c|c|}
\hline Construct & Definition & Key References \\
\hline Peers (H1) & $\begin{array}{l}\text { Peer learning and peer collaboration can help students accurately } \\
\text { estimate their academic work, assess their progress, and adjust their } \\
\text { learning strategies. }\end{array}$ & $\begin{array}{l}\text { Boud, 1995b; Boud et al., } \\
\text { 1999; Vygotsky, 1978; } \\
\text { Higgins et al, } 2002\end{array}$ \\
\hline Summative $(\mathrm{H} 2)$ & $\begin{array}{l}\text { Summative assessments report on learning achieved at a certain time, has } \\
\text { an important role but often not perceived in having a prominent function } \\
\text { in day-to-day teaching. Students however, may act on summative } \\
\text { feedback where there is a desire to achieve a better mark on a subsequent } \\
\text { occasion. }\end{array}$ & $\begin{array}{l}\text { Harlen and James 2006; } \\
\text { Smith and Gorard, } 2005\end{array}$ \\
\hline Generic (H3) & $\begin{array}{l}\text { General feedback or feed-forwards is considered to stimulate learning. } \\
\text { Generic feedback positioned as formative and provided in a collective } \\
\text { manner could support students' learning. }\end{array}$ & $\begin{array}{l}\text { Knight and Yorke 2003; } \\
\text { Higgins et al 2002; } \\
\text { Jonsson's } 2012\end{array}$ \\
\hline $\begin{array}{l}\text { Lecture exercises } \\
\text { (H4) }\end{array}$ & $\begin{array}{l}\text { Lecture exercises are seen to stimulate and enhance learning. Students } \\
\text { benefit from shared ideas and connect with other students during lecture } \\
\text { exercises and thus better engage with learning. }\end{array}$ & $\begin{array}{l}\text { Butler, Phillmann and } \\
\text { Smart, 2001; Bonwell, } \\
\text { 1996; McKeachie, } 1999\end{array}$ \\
\hline $\begin{array}{l}\text { Tutorial activities } \\
\text { (H5) }\end{array}$ & $\begin{array}{l}\text { In-class learning activities are found to enhance students' learning, } \\
\text { retention, and writing development. Tutorial activities and assessments } \\
\text { can also stimulate and construct self-generated feedback. }\end{array}$ & $\begin{array}{l}\text { Stewart, Myers and Culley } \\
\text { 2010; Nietfeld, Cao and } \\
\text { Osborne } 2006\end{array}$ \\
\hline Experience (H6) & $\begin{array}{l}\text { Assessment is viewed by students as central to their university } \\
\text { experience. In higher education, feedback to students is hoped to } \\
\text { promote learning and lead to improvements in subsequent pieces of work } \\
\text { prepared by the student. How students receive, perceive and use that } \\
\text { feedback could create an overall positive or negative experience of that } \\
\text { course. }\end{array}$ & Orsmond et al., 2005 \\
\hline
\end{tabular}




\section{Results}

\section{Evaluation of Measurement Model}

To ensure the accuracy of the structural model analysis, the validity and reliability of the scale developed needed to be tested. Table 2 presents the descriptive statistics for measurement items that include minimum value, maximum value, mean and standard deviation. Table 3 presents the results obtained via the bootstrapping procedure including PLS loadings, T-statistics, Significance level, Composite Reliability, Average Variance Extracted (AVE) and Cronbach's alpha. The results suggest that our measurement model demonstrates sufficient discriminant validity and internal consistency. Chin (1998) suggests that the loading should be greater than 0.707. Most of the reflective scales demonstrated acceptable performance above the minimum value of composite reliability, which is greater than 0.7. Overall, the condition of the loading scores was met in this study and the T-statistics revealed that all the items were at a significance level of 99 percent. A measurement item of feedback from peers, which is peer2 (0.693859) and summative assessment feedback, which is sum3 (0.684087) present scores slightly lower than the threshold, but are in an acceptable range. Given that these are newly developed items and the scores are in an acceptable range, we included them in the model.

Composite reliability, AVE and Cronbach's alpha calculated by PLS are suitable for assessing internal consistency (Chin 1998). All the reflective scales demonstrated acceptable performance above the minimum value of composite reliability, which is greater than 0.7 . Additionally, the standard for reliability dictates that the AVE scales should exceed 0.5 , indicating that " 50 percent or more variance of the indicators should be accounted for" (Chin 1998, p. 321). A Cronbach's alpha of greater than 0.7 is regarded as an acceptable level of variable reliability. It can be seen that all the scales performed acceptably on this standard.

Furthermore, the discriminant validity can be evaluated by comparing the AVE of the latent variables and the correlations among the Latent Variables (LVs). Table 4 presents the correlation of variables and the variables' respective square roots of AVEs obtained by PLS analysis. It can be seen that most of the square roots of AVEs are significantly greater than their corresponding correlations, with an exception of task efficiency that shows slightly higher scores for data quality and overall benefits variables. This confirms that most of the indicators measuring a particular LV do not improperly overlap with other LVs' concepts and that discriminant validity has been met. In addition, the result of the cross-loadings analysis presented in Table 5 shows that the loading of each item on its corresponding variable is higher than the loading of items on any other variables. The results from the square roots of AVE and cross loading analysis demonstrate that all measurement scales have discriminant validity in an acceptable level (Zhu et al. 2010).

Following the confirmation of validity and reliability of the measurement model, the results of the structural model are presented below. 
Table 2 Descriptive statistics for measurement items

\begin{tabular}{|c|c|c|c|c|c|}
\hline Variables and measurement items & $\begin{array}{l}\text { No of } \\
\text { items }\end{array}$ & Min. & Max. & Mean & $\overline{\text { Std. Deviation }}$ \\
\hline Feedback from Peers & 4 & & & & \\
\hline Peer1 & & 1 & 5 & 3.63 & .845 \\
\hline Peer2 & & 1 & 5 & 3.92 & .823 \\
\hline Peer3 & & 1 & 5 & 3.35 & .969 \\
\hline Peer4 & & 1 & 5 & 3.40 & .935 \\
\hline Summative Assessment Feedback & 3 & & & & \\
\hline Sum1 & & 1 & 5 & 3.78 & .852 \\
\hline Sum2 & & 1 & 5 & 3.92 & .742 \\
\hline Sum3 & & 1 & 5 & 3.71 & 1.08 \\
\hline Generic Assessment Feedback & 3 & & & & \\
\hline Gen1 & & 1 & 5 & 3.67 & .896 \\
\hline Gen2 & & 1 & 5 & 3.63 & .971 \\
\hline Gen3 & & 1 & 5 & 3.63 & .889 \\
\hline Lecture Exercises Feedback & 4 & & & & \\
\hline Lec1 & & 1 & 5 & 3.76 & .996 \\
\hline Lec2 & & 1 & 5 & 3.73 & 1.064 \\
\hline Lec3 & & 1 & 5 & 3.65 & 1.032 \\
\hline Lec4 & & 1 & 5 & 3.67 & 1.028 \\
\hline Tutorial Activities Feedback & 5 & & & & \\
\hline Tut1 & & 1 & 5 & 3.71 & 1.021 \\
\hline Tut2 & & 1 & 5 & 3.81 & .994 \\
\hline Tut3 & & 1 & 5 & 3.92 & 1.00 \\
\hline Tut4 & & 1 & 5 & 3.45 & 1.12 \\
\hline Tut5 & & 1 & 5 & 3.83 & .960 \\
\hline Overall Perception of Feedback & 4 & & & & \\
\hline Per1 & & 1 & 5 & 3.53 & .913 \\
\hline Per2 & & 1 & 5 & 3.55 & 1.017 \\
\hline Per3 & & 1 & 5 & 3.71 & .859 \\
\hline Per4 & & 1 & 5 & 3.63 & .944 \\
\hline Overall Learning Experience & 4 & & & & \\
\hline Exp1 & & 1 & 5 & 3.20 & 1.16 \\
\hline Exp2 & & 1 & 5 & 3.52 & 1.17 \\
\hline Exp3 & & 1 & 5 & 3.28 & 1.19 \\
\hline Exp4 & & 1 & 5 & 3.81 & .982 \\
\hline
\end{tabular}


Table 3 Summary of statistics for evaluating measurement model

\begin{tabular}{|c|c|c|c|c|c|c|c|}
\hline $\begin{array}{c}\text { Types of } \\
\text { variables }\end{array}$ & Variables and items & PLS loadings & T-statistics & $\begin{array}{c}\text { Significanc } \\
\text { e level }\end{array}$ & $\begin{array}{l}\text { Composite } \\
\text { Reliability }\end{array}$ & AVE & $\begin{array}{c}\text { Cronbach's } \\
\text { Alpha }\end{array}$ \\
\hline \multirow[t]{5}{*}{ Independent } & Feedback from Peers & & & & 0.886018 & 0.661852 & 0.826758 \\
\hline & Peer1 & 0.830221 & 13.483096 & 0.01 & & & \\
\hline & Peer2 & 0.693859 & 8.027277 & 0.01 & & & \\
\hline & Peer3 & 0.867096 & 20.194169 & 0.01 & & & \\
\hline & Peer4 & 0.851378 & 12.447178 & 0.01 & & & \\
\hline \multirow[t]{4}{*}{ Independent } & $\begin{array}{l}\text { Summative } \\
\text { Assessment } \\
\text { Feedback }\end{array}$ & & & & 0.880078 & 0.713281 & 0.795767 \\
\hline & Sum1 & 0.900308 & 26.092548 & 0.01 & & & \\
\hline & Sum2 & 0.928070 & 53.531903 & 0.01 & & & \\
\hline & Sum3 & 0.684087 & 5.831883 & 0.01 & & & \\
\hline \multirow[t]{4}{*}{ Independent } & $\begin{array}{l}\text { Generic Assessment } \\
\text { Feedback }\end{array}$ & & & & 0.904831 & 0.760233 & 0.843075 \\
\hline & Gen 1 & 0.856553 & 23.611575 & 0.01 & & & \\
\hline & Gen2 & 0.898614 & 48.225687 & 0.01 & & & \\
\hline & Gen3 & 0.859946 & 19.661001 & 0.01 & & & \\
\hline \multirow[t]{5}{*}{ Independent } & $\begin{array}{l}\text { Lecture Exercises } \\
\text { Feedback }\end{array}$ & & & & 0.920956 & 0.745089 & 0.884637 \\
\hline & Lec1 & 0.809867 & 17.946790 & 0.01 & & & \\
\hline & Lec2 & 0.817959 & 13.537261 & 0.01 & & & \\
\hline & Lec3 & 0.885401 & 32.087773 & 0.01 & & & \\
\hline & Lec4 & 0.933531 & 57.057405 & 0.01 & & & \\
\hline \multirow[t]{6}{*}{ Independent } & $\begin{array}{l}\text { Tutorial Activities } \\
\text { Feedback }\end{array}$ & & & & 0.941153 & 0.762439 & 0.922006 \\
\hline & Tut1 & 0.910753 & 35.661795 & 0.01 & & & \\
\hline & Tut2 & 0.779548 & 10.696888 & 0.01 & & & \\
\hline & Tut3 & 0.923346 & 46.721095 & 0.01 & & & \\
\hline & Tut4 & 0.863139 & 24.876303 & 0.01 & & & \\
\hline & Tut5 & 0.881733 & 26.688230 & 0.01 & & & \\
\hline \multirow[t]{5}{*}{ Mediating } & $\begin{array}{l}\text { Overall Perception } \\
\text { of Feedback }\end{array}$ & & & & 0.939290 & 0.794585 & 0.913893 \\
\hline & Per1 & 0.886301 & 31.762451 & 0.01 & & & \\
\hline & Per2 & 0.891968 & 34.769073 & 0.01 & & & \\
\hline & Per3 & 0.902987 & 39.110952 & 0.01 & & & \\
\hline & Per4 & 0.884203 & 27.877169 & 0.01 & & & \\
\hline \multirow[t]{5}{*}{ Dependent } & $\begin{array}{l}\text { Overall Learning } \\
\text { Experience }\end{array}$ & & & & 0.954661 & 0.840449 & 0.936733 \\
\hline & Exp1 & 0.910712 & 43.712167 & 0.01 & & & \\
\hline & Exp2 & 0.929664 & 67.930538 & 0.01 & & & \\
\hline & Exp3 & 0.944696 & 70.263863 & 0.01 & & & \\
\hline & Exp4 & 0.880724 & 29.114165 & 0.01 & & & \\
\hline
\end{tabular}


Table 4 Correlation of variables compared to square root of AVEs

\begin{tabular}{|c|c|c|c|c|c|c|c|}
\hline Measures & 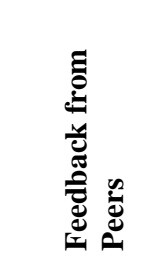 & 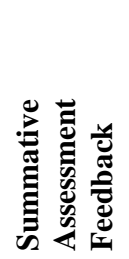 & 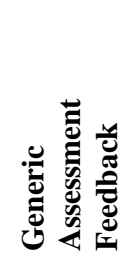 & 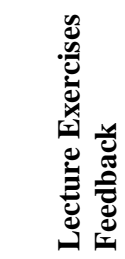 & 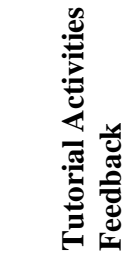 & 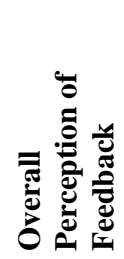 & 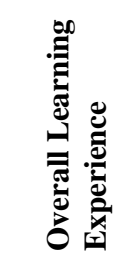 \\
\hline Feedback from Peers & $0.813543^{*}$ & & & & & & \\
\hline $\begin{array}{l}\text { Summative } \\
\text { Assessment } \\
\text { Feedback }\end{array}$ & 0.493454 & 0.84456 & & & & & \\
\hline $\begin{array}{l}\text { Generic Assessment } \\
\text { Feedback }\end{array}$ & 0.405088 & 0.541435 & 0.863185 & & & & \\
\hline $\begin{array}{l}\text { Lecture Exercises } \\
\text { Feedback }\end{array}$ & 0.514922 & 0.475955 & 0.637015 & 0.873178 & & & \\
\hline $\begin{array}{l}\text { Tutorial Activities } \\
\text { Feedback }\end{array}$ & 0.395152 & 0.585178 & 0.626075 & 0.521824 & 0.891395 & & \\
\hline $\begin{array}{l}\text { Overall Perception of } \\
\text { Feedback }\end{array}$ & 0.432918 & 0.680187 & 0.738385 & 0.617784 & 0.570445 & 0.91676 & \\
\hline $\begin{array}{l}\text { Overall Learning } \\
\text { Experience }\end{array}$ & 0.268180 & 0.371678 & 0.602116 & 0.555638 & 0.571571 & 0.636384 & 1.00000 \\
\hline
\end{tabular}

*Figures in bold are the square roots of AVEs.

Table 5 Cross-loadings results

\begin{tabular}{|c|c|c|c|c|c|c|c|}
\hline & 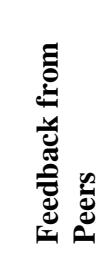 & 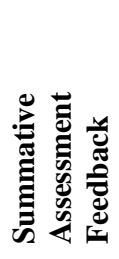 & 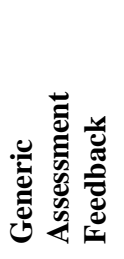 & 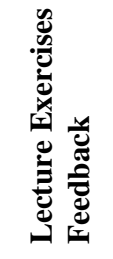 & ע & |c. & 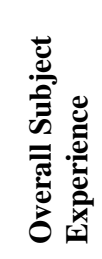 \\
\hline Peer1 & 0.830221 & 0.400516 & 0.251501 & 0.392791 & 0.260374 & 0.372224 & 0.109350 \\
\hline Peer2 & 0.693859 & 0.458133 & 0.345346 & 0.419583 & 0.430765 & 0.356295 & 0.313612 \\
\hline Peer3 & 0.867096 & 0.378741 & 0.407801 & 0.45993 & 0.331714 & 0.373758 & 0.258925 \\
\hline Peer4 & 0.851378 & 0.351496 & 0.300935 & 0.387979 & 0.242969 & 0.283694 & 0.182044 \\
\hline Sum1 & 0.408867 & 0.900308 & 0.510575 & 0.443086 & 0.582032 & 0.610857 & 0.319669 \\
\hline Sum2 & 0.451087 & 0.92807 & 0.558967 & 0.455898 & 0.524474 & 0.673371 & 0.405046 \\
\hline Sum3 & 0.403839 & 0.684087 & 0.238709 & 0.27900 & 0.346832 & 0.396056 & 0.175137 \\
\hline Gen1 & 0.411912 & 0.562111 & 0.856553 & 0.547042 & 0.611959 & 0.670875 & 0.529715 \\
\hline Gen2 & 0.328857 & 0.416507 & 0.898614 & 0.544777 & 0.52661 & 0.699596 & 0.521572 \\
\hline Gen3 & 0.313278 & 0.434196 & 0.859946 & 0.581842 & 0.491037 & 0.540629 & 0.525682 \\
\hline Lec1 & 0.498938 & 0.426832 & 0.57800 & 0.809867 & 0.513606 & 0.542907 & 0.375133 \\
\hline Lec2 & 0.434624 & 0.491146 & 0.553805 & 0.817959 & 0.467801 & 0.47393 & 0.468553 \\
\hline Lec3 & 0.387949 & 0.364268 & 0.499478 & 0.885401 & 0.372743 & 0.540932 & 0.509145 \\
\hline Lec4 & 0.455906 & 0.374223 & 0.569446 & 0.933531 & 0.451003 & 0.567975 & 0.562159 \\
\hline
\end{tabular}




\begin{tabular}{|l|c|c|c|c|c|c|c|}
\hline Tut1 & 0.344399 & 0.538371 & 0.609674 & 0.503115 & 0.910753 & 0.533143 & 0.522001 \\
\hline Tut2 & 0.261691 & 0.492905 & 0.331914 & 0.392619 & 0.779548 & 0.337144 & 0.461216 \\
\hline Tut3 & 0.271448 & 0.528661 & 0.55726 & 0.390693 & 0.923346 & 0.531127 & 0.587328 \\
\hline Tut4 & 0.396042 & 0.490975 & 0.601035 & 0.464922 & 0.863139 & 0.56073 & 0.382404 \\
\hline Tut5 & 0.437584 & 0.51354 & 0.570106 & 0.52318 & 0.881733 & 0.478601 & 0.555214 \\
\hline Per1 & 0.399323 & 0.574322 & 0.624072 & 0.554035 & 0.487053 & 0.886301 & 0.483099 \\
\hline Per2 & 0.419159 & 0.636465 & 0.676377 & 0.641553 & 0.537967 & 0.891968 & 0.561532 \\
\hline Per3 & 0.380574 & 0.592477 & 0.673062 & 0.54507 & 0.519487 & 0.902987 & 0.636551 \\
\hline Per4 & 0.345064 & 0.619677 & 0.6558 & 0.459913 & 0.486647 & 0.884203 & 0.578486 \\
\hline Exp1 & 0.223371 & 0.240474 & 0.5963 & 0.532903 & 0.496765 & 0.558895 & 0.910712 \\
\hline Exp2 & 0.332902 & 0.45055 & 0.542084 & 0.52963 & 0.552692 & 0.682363 & 0.929664 \\
\hline Exp3 & 0.268786 & 0.311076 & 0.579376 & 0.488392 & 0.499649 & 0.560548 & 0.944696 \\
\hline Exp4 & 0.129409 & 0.338357 & 0.489483 & 0.482499 & 0.545558 & 0.505957 & 0.880724 \\
\hline
\end{tabular}

\section{Structural Model Results}

The results of the structural model generated by PLS are presented in Figure 2. The predictiveness of the model can be assessed by the $\mathrm{R}^{2}$ of the dependent variables. The results show that $\mathrm{R}^{2}$ of the overall course experience is 0.405 , which indicates that overall perception of feedback accounted for 40 percent of the variance of the overall perception of learning experience variable. In addition, the $\mathrm{R}^{2}$ of the overall perception of feedback is 0.673 , which indicates that independent variables (feedback from peers, summative assessment feedback, generic assessment feedback, lecture exercises feedback and tutorial activities feedback) accounted for 63 percent of the variance of the overall perception of feedback variable.

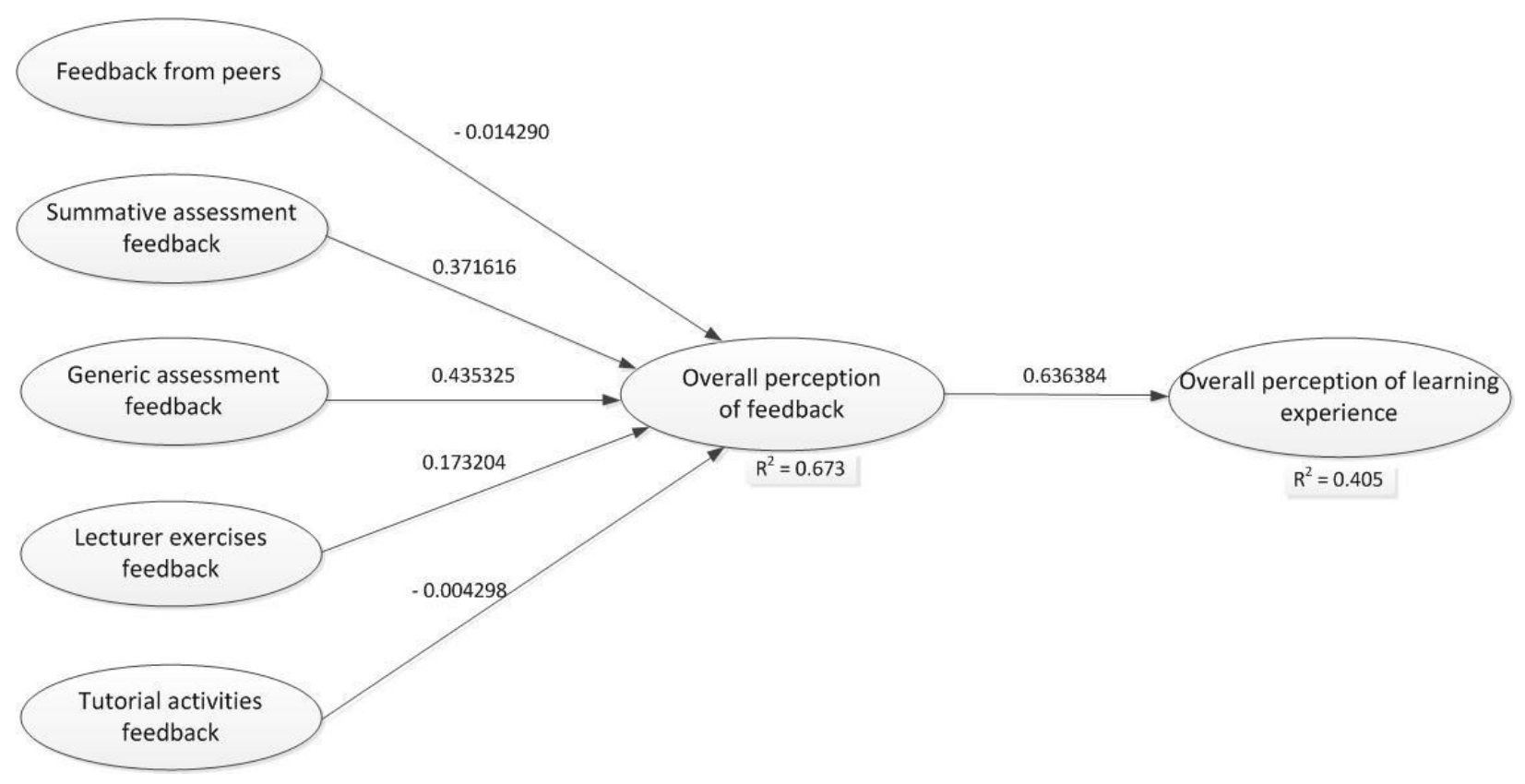

Figure 2: Results of statistical analysis 
Table 6 Summary of path coefficient test results

\begin{tabular}{|c|c|c|c|c|c|}
\hline & Hypothesis & $\begin{array}{l}\text { Actual } \\
\text { Effect }\end{array}$ & Path Coefficient & T-statistics & $\begin{array}{c}\text { Significance } \\
\text { Level }\end{array}$ \\
\hline $\begin{array}{l}\text { Feedback from Peers } \rightarrow \text { Overall } \\
\text { Perception of Feedback }\end{array}$ & $\mathrm{H} 1$ & - & 0.014290 & 0.150208 & Not significant \\
\hline $\begin{array}{l}\text { Summative Assessment Feedback - } \\
>\text { Overall Perception of Feedback }\end{array}$ & $\mathrm{H} 2$ & + & 0.371616 & 4.062722 & 0.01 \\
\hline $\begin{array}{l}\text { Generic Assessment Feedback -> } \\
\text { Overall Perception of Feedback }\end{array}$ & H3 & + & 0.435325 & 4.852619 & 0.01 \\
\hline $\begin{array}{l}\text { Lecture Exercises Feedback - > } \\
\text { Overall Perception of Feedback }\end{array}$ & $\mathrm{H} 4$ & + & 0.173204 & 1.348358 & Not significant \\
\hline $\begin{array}{l}\text { Tutorial Activities Feedback -> } \\
\text { Overall Perception of Feedback }\end{array}$ & H5 & - & 0.004298 & 0.052972 & Not significant \\
\hline $\begin{array}{l}\text { Overall Perception of Feedback -> } \\
\text { Overall Learning Experience }\end{array}$ & H6 & + & 0.636384 & 10.665706 & 0.01 \\
\hline
\end{tabular}

Table 6 presents the statistical outcome obtained through the bootstrapping procedure of PLS (that is actual effect, path coefficient, T-statistics, and significance level). The statistical findings support hypotheses 2,3 and 6 and reject hypotheses 1, 4 and 5. This indicates that summative assessment feedback and, generic assessment feedback have significant positive effects on the overall perception of feedback, while the overall perception of feedback has significant positive effect on the overall perception of learning experience. On the other hand, feedback from peers, lecture exercises feedback and tutorial activities feedback do not have significant influence on the respondents' learning experiences in the IS course.

The path coefficient between overall perception of feedback and overall learning experience shows the strongest relationship of 0.636384 at 99 percent significance level. This implies that when students have positive attitude toward the feedback that they receive, they are likely to have a better learning experience.

In terms of interdependent variables that influence the overall perception of feedback, the result shows that the path coefficient between generic assessment feedback and overall perception of feedback has the strongest relationship with 0.435325 path coefficient, followed by summative assessment feedback with 0.371616 path coefficient at 99 percent significance level. This implies that students' perceptions of generic and summative assessment feedback have a strong influence on the overall perception of feedback received.

\section{Analysis and Discussion}

With the objective of understanding the contribution of feedback mechanisms on an overall perception of feedback and a favourable experience in an introduction IS course, empirical data were collected, based on a survey instrument derived from the literature. The feedback mechanisms tested were: feedback by peers; summative feedback on assessments; generic feedback on assessments; feedback on lecture exercises; and feedback on tutorial activities. These feedback mechanisms were implemented as part of the course design as they were considered to best align with the mode of delivery, course content, learning objectives, anticipated graduate attributes, and the student cohort.

In responding to the first research question, 'What feedback mechanisms are perceived as important by students in an introductory IS course?' the results indicate that assessment-related feedback, both generic (formative) and summative, were perceived as significant to formulating an overall perception of feedback in this context. While the perception of the importance of summative feedback was somewhat anticipated (e.g. Smith and Gorard 2005), the fact that students placed significant importance on formative assessment feedback was particularly interesting. Anecdotally, the generic assessment feedback aroused students' interest in reconsidering their own assessment outcomes. This included contrasting their work with common mistakes and key characteristics of top answers noted 
in the generic feedback document and the verbal feedback provided. Consequently, this promoted a degree of selfassessment and reflection demonstrated through students' questions and acknowledgements in their discussions and consultations with instructors. These were enabled by the very detailed formative feedback provided along with the summative feedback, and linking each question/solution guideline back to the learning objective and materials covered in the course. This could also indicate that students may have a more favourable perception of formative feedback that is made explicit, documented, and formalised.

The fact that other forms of formative feedback were not perceived particularly significant in positively impacting perceptions of overall feedback and learning experience was noteworthy. As noted above, such feedback ranged from peer feedback, including a peer-assessed formative quiz, and weekly feedback on joint projects and activities, as well as formative feedback from instructors on lecture exercises and tutorial activities. With the feedback derived from lecture and tutorial exercises, it was hoped that students would become familiar with the expectations of teaching and learning in the IS course, and be prepared to reflect on and scaffold the feedback progressively towards tasks that are ultimately assessed as tangible evidence of their learning in the course. However, what the results indicate are that first year IS students are overwhelmingly assessment focused. This is consistent with several studies in the 1970s that found that assessments had a stronger influence on students than the actual teaching (Snyder, 1971; Miller and Parlett, 1974), either due to the idea of the 'hidden curriculum' namely, expected academic norms that are not explicitly stated (Snyder, 1971) or cues about what was actually rewarded in the assessment system (Miller and Parlett, 1974). In contrast, a recent National Schools Survey (NSS) in the UK conducted on behalf of the UK Higher Education Funding Council of England published that whilst students are most satisfied with teaching, they are least happy with assessment and feedback (HEFCE 2014). Our findings, in light of the former research about assessments influencing students rather than actual teaching, and the latter findings of the NSS, encourage educators to consider the assessment systems, what cues are being conveyed by the assessments and its relationship with the students' perceptions of a satisfactory learning experience. Some forms of assessment can be said to detract students from actual learning and comprehensive reflection. According to Ilgen and Davis (2000), feedback can detract from student learning if it is linked to confusion, anxiety, embarrassment and confidence. Others, for example, 'closedform' assessments like multiple choice or short answer questions may merely provide students with a grade or a mark to indicate their performance levels but may not always translate into reflection and knowledge building. Some forms of assessment, like exams may be answered successfully by students though question spotting, memorizing and having good essay-writing skills but this could make the assessment of actual learning outcomes untenable (Rust 2002). The significant perception of generic feedback in the authors' context validates the choice of a casebased assessment strategy and the provision of regular detailed generic feedback.

Alternatively, the fact that non-assessment related generic feedback was not found to be significant could also be due to students needing guidance in interpreting such feedback in order for them to better appreciate it (Jolly and Boud 2013; Weaver 2006). Guidance could then help them link the other forms of formative feedback to how they might improve, allowing them to work towards better performance and having a strategy to get there. While this has been the case in our context, a deeper maturity and awareness of the broader competencies acquired through multiple forms of feedback seems to take longer to develop. This calls for further research in later years of study in order to explore the development of a broader competency based-perspective. It is important to determine the level/timeframe at which an IS student would start to increasingly think of themself as prospective professionals with competencies, skills and graduate attributes that go beyond assessment based proficiencies to industry oriented competencies, with the objective of transferring what they have learnt into addressing real world problems and different contexts (Kirschner and Van Merriënboer 2008).

Moreover, according to Dreifuerst (2009), openness to feedback is a primary role for the learner, and students can be coached and guided to receive feedback that facilitates positive learning. Cognitive and developmental teaching approaches may therefore prove essential in developing a better perspective of such feedback, where student develop a conception of themselves as learners and "learn how to learn" (Toohey 1999, p.55). This development may take a longer timeframe to develop, possibly through being reinforced over multiple semesters. In such approaches, knowledge is personally constructed; therefore the questioning skills of teachers are of utmost importance, as they help students attain depth in their critical analysis which they would be unlikely to attain otherwise. Students' intellectual development is at the heart of these approaches, and their interests and motivations are continuously nurtured in an encouraging environment, rich with positive reinforcement and ongoing feedback, support and guidance. This may contribute to the development of a deeper appreciation of other forms of formative feedback and their significance. 


\section{Feedback for Thought}

Importantly, feedback provides students with an experiential base for reflection (Quinton and Smallbone 2010) that in turn, prompts deeper learning (Higgins et al., 2002). Therefore reflection on feedback needs to be at the core of learning for feedback to be effective (Mutch 2003, Quinton and Smallbone 2010).Towards such effect, there seems to be a need for a holistic view of reflective feedback to mirror Brookfield's (1995) four lenses recommended for critical and reflective teachers, which invites instructors to reflect on their teaching through adopting a student lens, a peer lens, a literature lens, and an autobiographical lens. The authors therefore call for corresponding lenses for a critical and reflective learner, which entice the learner to improve their learning processes through critically reflecting on all constituents of the feedback they receive from their instructors, peers, pedagogical literature, and autobiographical self-evaluation.

Learner's Instructor Lens: Where students take the opportunity to reflect on the feedback they receive from their instructor(s) on assessment activities as well as tasks that are not directly-assessable (e.g. Oosterbaan et al 2010). This extends beyond summative assessment, to also encompass formative feedback on class activities, prescriptive advice and guidelines, and best practice examples and models proposed by instructors. Such reflection entails a refocus on learning and sense-making (rather than an exclusive assessment oriented focus) from the student's perspective. These could be driven - in part - by instructors designing the curriculum to incorporating industry based examples, activities, and presentations that demonstrate to students the core competencies transferable to their future careers (Kirschner and Van Merriënboer 2008).

Learner's Peer Lens: Where students reflect on formative and summative feedback they receive from other students in their cohort. The pivotal role of peers in feedback processes is well-supported since peers are often the "most accessible and most involved parties in the learning experience" (Ladyshewsky, 2013 p. 175). This could arise from group-work activities and/or from peer-assessment exercises. One mechanism that could be incorporated by instructors to encourage such reflection is through providing activities and frameworks where such feedback is documented by students, and reports produced critically analysing the feedback received along with mechanisms put in place to act on such feedback. This may enable a habitual engagement with the feedback received from peers, along with a critical evaluation and appreciation of such feedback. This also equips students with essential skills in providing constructive feedback to others and in reflecting and acting on feedback from peers, both important skills for successful collegial participation and career progress.

Learner's Literature Lens: To assist students in viewing themselves as learners and "learn how to learn" (Toohey 1999, p.55), the literary lens could be incorporated. Such lens would provide students with an understanding of pedagogical findings in the academic literature. Instructors could facilitate this by providing students with access to seminal articles on learning and teaching to reflect upon, such as the SOLO Taxonomy (Biggs and Collis 1982), through which students can reflect on their understanding and expressions of knowledge. This calls upon instructors to supplement discipline specific readings (e.g. on Information Systems theory), with pedagogical readings aiming at enabling the student's reflective practice on their own learning triggers and processes. Anecdotally, students found such materials very helpful in the context of this course.

Learner's Autobiographical Lens: Here, students independently reflect on their own learning (Nicol and Macfarlane-Dick 2006), sense-making, and output. This could come in the form of self-assessment on assignment tasks. But more importantly, it could take the form of continuous reflection on learning processes and outcomes aiming at continuous learning, value creation, and personal growth. Instructors could encourage this through rolemodelling and providing students with personal insights of the instructor's autobiographical reflection on issues they face personally and professionally.

Engaging in such multidimensional reflection, and often documenting such reflection, will provide for optimal learning-teaching processes based on thorough learner's reflection and appreciation of the multiple forms of feedback provided. Curricular designers, coordinators, and instructors could facilitate such reflections through providing students with tools, opportunities, and resources aimed at developing critical and reflective practice. This would mean that time for reflection on verbal and written feedback need to be allocated and embedded in a course program, for example, during classroom sessions, in order to provide students with the opportunities for selfassessment, feeding forward and self-development (Mutch 2003; Quinton and Smallbone 2010).

In relation to the second research question raised by this study, the results clearly indicate a very strong relationship between an overall perception of positive feedback and a favourable experience in an introductory IS course. This aligns with previous research that highlights the importance of feedback in the learning process (Sadler 1998; Orsmond et al. 2005; Hattie et al. 1996; Black and Wiliam 1998; Hattie and Jaeger 1998). However, the empirical findings shed a particular light on the perception of a positive experience that a student encounters through 
formulating a positive perception of feedback they receive. Consequently, it could be argued here that feedback is fundamental for a positive learning experience. It is said that emotions form part of learning and therefore from part of feedback (Molloy, Borrell-Carrio \& Epstein, 2013). Without an overall perception of positive feedback, students might avoid further feedback opportunities or discount feedback altogether (Molloy, Borrell-Carrio \& Epstein, 2013). This validates the approach taken in this course in providing a broad-spectrum of feedback mechanisms, which, for instance, includes for assessments: individual summative feedback; individual written formative feedback; generic written feedback guide; generic verbal feedback from the marker at each tutorial session; generic verbal feedback from the course coordinator; individual verbal feedback opportunities from the marker (should the student request it); and individual verbal feedback opportunities from the course coordinator. Similar relevant feedback processes were also made available for all learning activities and exercises in the course. Anecdotally, these seem to have contributed to a positive perception of experience also noted in the students' formal evaluation of the course.

Furthermore, encouraging students to engage with their learning through reflective practice is one way to inculcate an overall favourable experience of learning. In this light, the adoption of Brookfields' reflective lenses by students can help students review their own assumptions about learning and feedback. This also means that they are able to detect their own personal assumptions about assessment and feedback that they might have believed to be in their own best interests but may be detrimental in the long term (Brookfield 2002). Therefore, reflection to reexamine learning experiences and outcomes based on feedback can be facilitated and such perceptions and outcomes could be further enhanced through the implementation of the reflective practices noted above.

\section{Implications}

\section{Theoretical}

To the authors' knowledge, this is the first study to provide a holistic model for understanding the perceptions of different feedback mechanisms, and how they contribute to an overall view of feedback. This, therefore, provides an important contribution to the pedagogical literature with a predictive model, based on the PLS technique, that has been empirically tested. Moreover, the findings highlight the importance of feedback to learners' perceived experience in an introductory course which was also found to be very significant.

The findings provide for an insight into perceptions of feedback by the learner, which go beyond traditional research in the pedagogical feedback context, and its general prescriptive focus to providing feedback. This calls for future research that encompasses prescription of good feedback practice as well as the perceptions of such feedback by students - along with reflective means to improve such perceptions and learning processes. This research therefore extends the predominant research practice from 'prescription' about feedback provision, to also encompass students' 'perception', 'reflection', and 'experience'.

\section{Practical}

From a practical pedagogical perspective, the study highlights the importance of both summative as well as generic feedback on assessment work. It is therefore recommended that instructors provide clear and detailed feedback that link back to course materials and learning objectives. Importantly, based on the findings of this research, the authors propose that survey instruments for students' evaluation of courses and instructors need to include items for evaluation of different forms of feedback. This would provide curricular designers and instructors with a clearer and more holistic view of the effectiveness of feedback processes deployed in a particular course. Coordinators and instructors are advised to administer such evaluations themselves (should this not infringe on academic policies) if there is no opportunity to do so through university processes, or if they get no access to such results in a clear, comprehensive, and timely manner.

Additionally, embedding and linking the practice of facilitated reflection for first year students through multiple forms of formative and summative feedback provides an opportunity to make learning deeper and more visible. These forms of feedback need to be explicit, documented, formalised, and linked back to course materials and the learning objectives to aid effective reflection. Moreover, it is also advisable that multiple evaluations are undertaken over the course of a semester (e.g. week 4; week 8; as well as end of semester) so that remedial and reflective measures could be put into practice. 


\section{Conclusion and Future Research}

The findings indicate that in the context of this introductory IS course, summative and generic (formative) assessment feedback were perceived by students as significant in contributing towards an overall favorable assessment of feedback in the course. In turn, a positive overall assessment of feedback was found as significant towards formulating a positive experience in an introductory IS course.

Notwithstanding its contributions and implications, this study has several limitations. The empirical data collection was conducted for a single cohort of students enrolled in a single course. Future research could target different cohorts particularly at latter years of university education to see if such feedback perceptions change as students gain academic competence and maturity. Further insight could also emanate from studying students in different degree programs and in different cultural contexts. Moreover, a limited set of feedback mechanisms were covered in this study, consisting of five feedback mechanisms, relevant to the course content and delivery mode. In other courses, learners may benefit from alternative feedback mechanisms which could also be examined. An investigation of students' perceptions of the constituents of feedback may also clarify explicitly whether particular feedback elements are more recognisable and actionable. Additionally, research approaches that accommodate qualitative data may also provide good insight as to why and how feedback perceptions emerge and evolve over time, and how reflective abilities and practices may be embedded in the curriculum for a more positive overall learning experience.

The findings call for a more thorough appreciation and investigation of feedback perceptions by learners and into developing a broader perspective to feedback and reflection, particular in tertiary courses.

\section{Acknowledgements}

The authors wish to acknowledge the University of Technology Sydney for its provision of a competitive First Year Experience Grant in support of this study.

\section{REFERENCES}

Archer, J. C. 2010. "State of the Science in Health Professional Education: Effective Feedback," Medical Education (44:1), pp. 101-108.

Azevedo, R., and Bernard, R. M. 1995. "A Meta-analysis of the Effects of Feedback in Computer-based Instruction," Journal of Educational Computing Research (13:2), pp. 111-127.

Beaumont, C., O’Doherty, M. and Shannon, L. 2011. "Reconceptualising Assessment Feedback: A Key to Improving Student Learning?," Studies in Higher Education (36:6), pp. 671-687.

Black, P., and Wiliam, D. 1998. "Assessment and Classroom Learning," Assessment in Education: Principles, Policy and Practice (5:1), pp. 7-74.

Bloom, B. S., and Krathwohl, D. R. 1956. "Taxonomy of Educational Objectives: The Classification of Educational

Goals. Handbook I: Cognitive domain," New York: David McKay.

Bonwell, C. C. 1996. "Enhancing the lecture: Revitalizing a Traditional Format," in Using Active Learning in College Classes: A Range of Options for Faculty, T. E. Sutherland and C. C. Bonwell (eds.), San Francisco: Jossey-Bass, pp. 31-44.

Boud, D. 1995. "Enhancing Learning Through Self-assessment, ” London: Kogan Page.

Boud, D., Cohen, R. and Sampson, J. 1999. "Peer Learning and Assessment," Assessment and Evaluation in Higher Education (24:4), pp. 413-426.

Biggs J and Collis, K 1982. "Evaluating the Quality of Learning: the SOLO Taxonomy", Academic Press, New York

Brinkworth, R., McCann, B., Matthews, C. and Nordstrom, K. 2009. "First Year Expectations and Experiences: Student and Teacher Perspectives," High Education (58:2), pp:157-173.

Brockbank, A. and McGill, I. 1998. "Facilitating Reflective Learning in Higher Education," Buckingham: Society for Research into Higher Education and Open University Press.

Brookfield, S. 1995. “Becoming a Critically Reflective Teacher,” San-Francisco: Jossey-Bass. 
Brookfield, S.D. 2002, "Using the lenses of critically reflective teaching in the community college classroom", New Directions for Community Colleges, vol. 2002, no. 118, pp. 31-8.

Brown, S., and Knight, P. 1994. "Assessing Learners in Higher Education, ” London: Kogan Page.

Butler, A., Phillman, K. and Smart, L. 2001. "Active Learning Within a Lecture: Assessing the Impact of Short, Inclass Writing Exercises," Teaching of Psychology (28:4), pp. 257-259.

Cartney, P. 2010. "Exploring the Use of Peer Assessment as a Vehicle for Closing the Gap Between Feedback Given and Feedback Used," Assessment and Evaluation in Higher Education (35:5), pp. 551-564.

Chin, W. W. 1998. "Issues and Opinion on Structural Equation Modeling". MIS Quarterly (22:1), pp. vii-xvi.

Cramp, A. 2011. "Developing First-year Engagement with Written Feedback," Active Learning in Higher Education (12:2), pp. 113-124.

Crisp, B. R. 2007. "Is it Worth the Effort? How Feedback Influences Students' Subsequent Submission of Assessable Work," Assessment and Evaluation in Higher Education (32:5), pp. 571-581.

DiPardo, A., and S.W. Freedman. 1988. "Peer Response Groups in the Writing Classroom: Theoretical Foundations and New Directions." Review of Educational Research (58:2), pp. 119-149.

Draper, S. W. 2009. "What are Learners Actually Regulating When Given Feedback?" British Journal of Educational Technology (40:2), pp. 306-315.

Dreifuerst, K.T. 2009, "The essentials of debriefing in simulation learning: a concept analysis," Nursing Education Perspectives, (30:2), pp. 109-14.

Eom, S.B., Wen, H.J., and Ashill, N. 2006. 'The Determinants of Students' Perceived Learning Outcomes and Satisfaction in University Online Education: An Empirical Investigation", Decision Sciences Journal of Innovative Education (4:2), pp. 215-35.

Epstein, M. L., Lazarus, A. D., Calvano, T. B., Matthews, K. A., Hendel, R. A., Epstein, B. B., and Broswic, G. M. 2002. "Immediate feedback assessment technique promotes learning and corrects inaccurate first responses," The Psychological Record (52:2), pp. 187-201.

Ferguson, P. 2011. "Student Perceptions of Quality Feedback in Teacher Education," Assessment and Evaluation in Higher Education (36:1), pp. 51-62.

Gibbs, G., and Simpson, C. 2004. "Conditions Under which Assessment Supports Students' Learning," Learning and Teaching in Higher Education (1:1), pp. 3-31.

Hackman, M.Z. and Walker, K.B. 1990, "Instructional Communication in the Televised Classroom: The Effects of System Design and Teacher Immediacy on Student Learning and Satisfaction”, Communication Education (39:3), pp. 196-206.

Harlen, W. and James, M. 1997. "Assessment and Learning: Differences and Relationships Between Formative and Summative Assessment," Assessment in Education: Principles, Policy and Practice (4:3), pp. 365-379

Harvey, L., and Knight, P. T. 1996. "Transforming Higher Education," Buckingham: Open University Press.

Hattie, J.A. 1987. "Identifying the Salient Facets of a Model of Student Learning: A Synthesis of Meta-analyses," International Journal of Educational Research (11:2), pp. 187-212.

Hattie, J., Biggs, J. and Purdie, N. 1996. "Effects of Learning Skills Intervention on Student Learning: A Metaanalysis," Review of Educational Research (66:2), pp. 99-136.

Hattie, J. and Jaeger, R. 1998. "Assessment and Classroom Learning: A Deductive Approach," Assessment in Education (5:1), pp. 111-122.

Hattie, J., and Timperley, H. 2007. "The Power of Feedback," Review of Educational Research (77:1), pp. 81-112.

HEFCE 2014. "National Student Survey results 2014", Higher Education Funding Council for England, http://www.hefce.ac.uk/lt/nss/results/2014/, viewed 12 October 2015.

Higgins, R., Hartley, P. and Skelton, A. 2001. "Getting the Message Across: The Problem of Communicating Assessment Feedback," Teaching in Higher Education, (6:2), pp. 269-274.

Higgins, R., Hartley, P., and Skelton, A. 2002. "The Conscientious Consumer: Reconsidering the Role of Assessment Feedback in Student Learning," Studies in Higher Education (27:1), pp. 53-64.

Horsburgh, M. 1999. "Quality Monitoring in Higher Education: The Impact on Student Learning," Quality in Higher Education (5:1), pp. 9-25.

Hounsell, D. 2003. "Student Feedback, Learning and Development, in Higher education and the lifecourse, M. Slowey and D. Watson (eds), Maidenhead: Open University Press, pp. 67-78.

Hounsell, D., V. McCune, J., Hounsell, and J. Litjens. 2008. "The Quality of Guidance and Feedback to Students," Higher Education Research and Development (27:1), pp. 55-67.

Hyland, P. 2000. "Learning from Feedback on Assessment," in The Practice of University History Teaching, P. Hyland and A. Booth (eds), Manchester: Manchester University Press, pp. 233-47.

Jonsson, A. 2012. "Facilitating Productive Use of Feedback in Higher Education," Active Learning in Higher 
Education (14:1), pp. 63-76.

Kirschner, P., and Van Merriënboer, J. 2008. "Ten steps to complex learning: A new approach to instruction and instructional design" In T. L. Good (Ed.), 21st Century Education: A Reference Handbook, Thousand Oaks: Sage, pp. 244-253.

Macfarlane-Dick, D., Matthew, B., Nicol, D., Ross, D., and Smith, B. 2004. "Enhancing student learning through effective formative feedback," Higher Education Academy (Generic Centre).

Knight, P. and Yorke, M. 2003. “Assessment, Learning and Employability,” Maidenhead: Open University Press.

Ladyshewsky, R. 2013. "The role of peers in feedback processes" in Feedback in Higher and Professional Education, Boud, D. and Molloy, E. (eds), Oxon: Routledge, pp.174-189.

Lizzio, A., and Wilson, K. 2008. "Feedback on Assessment: Students' Perceptions of Quality and Effectiveness," Assessment and Evaluation in Higher Education (33:3), pp. 263-275.

Long, M., Ferrier, F., and Heagney, M. 2006. "Stay, Play or Give it Away? Students Continuing, Changing or Leaving University Study in Their First Year," Centre for the Economics of Education and Training, Monash University.

McKeachie, W. J. 1994. "Teaching Tips: Strategies, Research, and Theory for College and University teachers," (9th ed.), Lexington, MA: D. C. Heath

McKeachie, W. J. 1999. "Teaching Tips: A Guidebook for the Beginning College Teacher (10th ed.), Lexington, MA: Heath.

Miller, C.M.I. and Parlett, M. 1974. "Up to the Mark: a study of the examination game," Guildford: Society for Research into Higher Education.

Molloy, E., Borrell-Carrio, F. \& Epstein, R. 2013. "The impact of emotions in feedback" in Feedback in Higher and Professional Education, Boud, D. and Molloy, E. (eds), Oxon: Routledge, pp.50-71.

Moreno, R. 2004. "Decreasing Cognitive Load for Novice Students: Effects of Explanatory Versus Corrective Feedback in Discovery-based Multimedia," Instructional Science (32:1-2), pp. 99-113.

Mutch, A. 2003. "Exploring the practice of feedback to students," Active Learning in Higher Education, (4:1), pp. 24-38.

Nicol, D. 2010. "Resituating feedback from the Reactive to the Proactive," in Feedback in Higher and Professional Education, Boud, D. and Molloy, E. (eds), Oxon: Routledge, pp.34-49.

Nicol, D. 2010. "From Monologue to Dialogue: Improving Written Feedback Processes in Mass Higher Education," Assessment and Evaluation in Higher Education (35:5), pp. 501-517.

Nicol, D.J., and Macfarlane-Dick, D. 2006. "Formative assessment and self-regulated learning: A model and seven principles of good feedback practice," Studies in Higher Education, (31), pp. 199-218.

Nietfeld, J. L., Cao, L., and Osborne, J. W. 2006. "The Effect of Distributed Monitoring Exercises and Feedback on Performance, Monitoring Accuracy, and Self-efficacy," Metacognition and Learning (1:2), pp. 159-179.

O’Donovan, B., M. Price, and C. Rust. 2004. "Know What I Mean? Enhancing Student Understanding of Assessment Standards and Criteria," Teaching in Higher Education (9:3), pp. 325-35.

Oosterbaan, A. E., van der Schaaf, M. F., Baartman, L. K., and Stokking, K. M., 2010. "Reflection During PortfolioBased Conversations," International Journal of Educational Research (49), pp. 151-160.

Orsmond, P., Merry, S. and Reiling, K. 2002. "The Use of Exemplars and Formative Feedback when Using Student Derived Marking Criteria in Peer and Self Assessment," Assessment and Evaluation in Higher Education (27:4), pp. 309-323.

Orsmond, P., Merry, S. and Reiling, K. 2005. "Biology Students' Utilization of Tutors' Formative Feedback: A Qualitative Interview Study," Assessment and Evaluation in Higher Education (30:4), pp. 369-386.

Orsmond, P., Merry, S. and Callaghan, A.C. 2004. "Implementation of a Formative Assessment Model Incorporating Peer and Self Assessment," Innovations in Education and Training International, (41:3), pp. 273-290.

Pridemore, D. R., and Klein, J. D. 1995. "Control of Practice and Level of Feedback in Computer-based Instruction," Contemporary Educational Psychology (20:4), pp. 444-450.

Race, P. 2001. "Using Feedback to Help Students to Learn,” York: The Higher Education Academy.

Ramaprasad, A. 1983. "On the Definition of Feedback," Behavioral Science (28:1), pp. 4-13.

Read, B., Francis, B. and Robson, J. 2005. "Gender, 'Bias', Assessment and Feedback: Analyzing the Written Assessment of Undergraduate Student Essays," Assessment and Evaluation in Higher Education (30:3), pp. 241-260.

Reynolds, M. and Trehan, K. 2000. “Assessment: A Critical Perspective,” Studies in Higher Education, (25:3), pp. $267-278$. 
Richardson, J.C. and Swan, K. 2003. "Examining Social Presence in Online Courses in Relation to Students' Perceived Learning and Satisfaction," Journal of Asynchronous Learning Networks (7:1), pp. 68-88.

Rust, C. 2002, "The Impact of Assessment on Student Learning: How Can the Research Literature Practically Help to Inform the Development of Departmental Assessment Strategies and Learner-Centred Assessment Practices?", Active Learning in Higher Education, vol. 3, no. 2, pp. 145-58.

Rust, C. 2007. "Towards a Scholarship of Assessment," Assessment and Evaluation in Higher Education, (32:2), pp. 229-237.

Sadler, D. R. 1989. "Formative Assessment and the Design of Instructional Systems," Instructional Science (18:2), pp. 119-144.

Sadler, D. R. 1998. "Formative Assessment: Revisiting the Territory," Assessment in Education: Principle,. Policy and Practice (5:1), pp. 77-85.

Shute, V. J. 2008. "Focus on Formative Feedback," Review of Educational Research (78:1), pp.153-189.

Smith, E. and Gorard, S. 2005. “'They Don't Give Us Our Marks': The Role of Formative Feedback in Student Progress," Assessment in Education (12:1), pp. 21-38.

Snyder, B.R. 1971. "The Hidden Curriculum," Cambridge, MA: MIT Press.

Stewart, T. L., Myers, A. C., and Culley, M. R. 2009. "Enhanced Learning and Retention Through "Writing to Learn" in the Psychology Classroom," Teaching of Psychology (37:1), pp. 46-49.

Toohey, S. 1999. "Designing Courses for Higher Education," Buckingham: The Society for Research into Higher Education and Open University Press.

Vygotsky, L.S. 1978. "Mind in Society," Cambridge, Mass.: Harvard University Press.

Weaver, M.R. 2006, "Do students value feedback? Student perceptions of tutors' written responses", Assessment \& Evaluation in Higher Education, (31:3), pp. 379-94.

Weimer, M. 2002. "Learner-centered Teaching: Five Key Changes to Practice," San Francisco: Wiley

Wiliam, D. 2011. "What is Assessment for Learning?" Studies in Educational Evaluation (37:1), pp. 3-14.

Winne, P. H., and Butler, D. L. 1994. "Student Cognition in Learning from Teaching," in International Encyclopaedia of Education (2nd ed), T. Husen and T. Postlewaite (eds.), Oxford, UK: Pergamon, pp. 57385745.

Zhu, Y., Li, Y., Wang, W.and Chen, J. 2010. "What Leads to Post-implementation Success of ERP? An Empirical Study of the Chinese Retail Industry," International Journal of Information Management (30:3), pp. 265276. 